\title{
Going beyond Kirkpatrick's Training Evaluation Model: The role of workplace factors in distance learning transfer
}

\author{
F.R. Aluko \\ Unit for Distance Education, \\ University of Pretoria, \\ Pretoria, \\ South Africa \\ Email: ruth.aluko@up.ac.za
}

\author{
O.K. Shonubi \\ Department of Education Management, \\ Law \& Policy Studies, \\ Faculty of Education, \\ University of Pretoria, Pretoria, South Africa \\ Email: shonubiololade@gmail.com
}

\begin{abstract}
This article emanates from a longitudinal study of the impact of a distance education programme for teacher training on graduates' job performance, in which the authors built on the findings of a previous pilot study. After using Kirkpatrick's Training Evaluation Model in a previous study, one of the authors found there to be a strong relationship between graduates' completion of the programme and their performance at school. However, the model does not probe factors that impede on transfer of learning. Quite a number of the graduate participants indicated that they were faced with this problem. In order to further probe this phenomenon, the authors fused Baldwin's Transfer of Training Model with the second level of Kirkpatrick's model by using a mixed-methods enquiry. It became clear that the organizational climate of schools has a strong influence on the transfer of learning in the workplace. Suggestions are presented on how educators and school managers can work together effectively.
\end{abstract}

Keywords: distance education, programme evaluation, transfer of learning, Kirkpatrick's Training Evaluation Model, Baldwin's Transfer of Training Model, professional development 


\section{Introduction}

One could agree with McKee (2010) that, due to the developmental deluge of pedagogies and technologies that have been facing distance education since its inception, pinning down its exact definition is challenging. Nevertheless, this model of delivery is regarded as being valuable, particularly due to its ability to promote access to learning and lifelong learning. Teacher education is one of the fields that has benefitted most from the distance education model (UNESCO, 2001).

Teachers involved in distance education are adults who cannot afford to leave their jobs due to family and social commitments, or fear of not having a job to come back to. There is a historical link between distance learning and adult education (Kovach and Montgomery, 2010).

Unfortunately, not much has been done to measure the impact of distance education training programmes on the professional practice of teachers (Fahy, Spencer and Halinski, 2007; Aluko, 2009). Research has shown that reports emanating from such evaluations can reveal the strengths and weaknesses of programmes, and can be used to improve them if necessary (Newcomer and Allen, 2008).

The evaluation of training programmes is a commonplace practice in the commercial sector to measure return on investment (ROI). In the US, for example, corporations spend billions of dollars annually to train their workforce; this has not abated despite the current economic crunch (Training Magazine, 2011).

In the education sector, there has also been increasing interest in evaluating training programmes in recent years, owing to increased pressure on education for greater accountability (Guskey, 2000).

Scholars have developed diverse frameworks and training models to evaluate these training programmes in the commercial sector. Some scholars have suggested the use of such models for research purposes (Tarouco and Hack, 2000). This is done in the interest of their potential to ensure accountability, and to provide feedback to all stakeholders. Boyle and Crosby (1997) have urged that the definition of success in higher education should include student satisfaction, learning proficiency, application skills and overall programme effectiveness. Commercial programme evaluation models encourage this.

Scholars have argued that, even though education is regarded by many as a social investment, there is a need to justify the large amount of money spent on 
it (Rumble, 2007; UNESCO, 2009). Such evaluations are particularly important within the landscape of South African education, since a large chunk of the country's budget is devoted to education and to the improvement of graduation rates (South Africa, 2012).

\section{Background to the study}

The Advanced Certificate in Education: Education Management (ACE: EM) programme presented by the University of Pretoria is a professional qualification that enables educators to develop their competencies or adopt new educator roles (South Africa, 2000). According to the Department of Education (South Africa, 2001), the specified overall learning outcomes of the ACE require a qualified practitioner at this level to be able to fulfil the role of a specialist education manager.

Thus, the university expects graduates to be highly competent in terms of knowledge, skills, principles, methods and procedures relevant to education management. This will ensure that graduates are prepared for a leadership role in education management, understand the role of ongoing evaluation and action research in developing competence within their chosen area of specialization, and are able to carry out basic evaluations and action research projects (University of Pretoria, 2011).

\section{Problem statement}

One of the most effective ways of raising the quality of education is to develop the means to train teachers who are already in service (Musset, 2010). Although many teachers receive their training through distance education, research provides little evidence of the impact of such programmes on the professional practice of teachers (Fahy et al., 2007; Aluko, 2009). This is due, among other things, to inadequate knowledge of the extent to which workplace factors militate against the transfer of knowledge. This is especially relevant to the South African context in which government aims to improve the poor leadership that exists in schools - a legacy inherited from the country's historical background (Swanepoel, 2008).

Stakeholders invest a lot of money in the professional development of teachers to update, develop and broaden the knowledge acquired during teachers' initial training and to provide them with new skills and professional understanding (Organisation for Economic Cooperation and Development, 2005). It is 
therefore important to study the extent to which the knowledge gained from such programmes is transferred to the workplace.

Popularising andragogy (the theory of adult learning), Michael Knowles (1984, cited in Smith, 2002) identifies five characteristics of adult learners: selfconcept, experience, readiness to learn, orientation to learning and (intrinsic) motivation. Adults are expected to transfer the knowledge and skills that they have acquired from training to their work environment. However, the possibility of this could depend on a number of factors. These are explored in this article. The research question that guides this study is: What is the role of workplace factors in distance learning transfer and to what extent does the new model suggested by the researchers help to highlight these factors?

\section{Training evaluation models underpinning the study}

In this study, we have used both Kirkpatrick's Training Evaluation Model and Baldwin's Transfer of Learning Model (Kirkpatrick, 1994; Baldwin and Ford, 1988 ) to make up for the inability of Kirkpatrick's model to address factors that could limit or promote transfer of learning.

\section{Transfer of learning model}

Although there are diverse schools of thought on the interchangeable use of the terms 'transfer of training' and' transfer of learning', the argument is beyond the scope of this article, and the terms are used interchangeably. Transfer of training generally relates to adult education, vocational or professional training or workplace education, and is defined as the degree to which trainees effectively apply knowledge, skills and attitudes gained in a training context to the job environment (Newstrom, 1984; Wexley and Latham, 1991, cited in Subedi, 2004).

For training to have occurred, learned behaviour must be applied to the job context and maintained over a period of time (Baldwin and Ford, 1988). It can be argued that, when it is difficult to apply what one has learnt due to work pressures, the training that was received was inoperable, does not add value to stakeholders, and was a waste of time and money.

However, it has been contested that transfer of training - or lack thereof - is a complex process that depends on a number of factors, including the intent or motivation of the learner (trainee characteristics), the workplace environment, including supervisory support (organizational environment and culture), and the 
instructional design, as well as delivery features (job relevance) of the training programme (Subedi, 2004).

The above confirms the findings of previous studies. For example, Baldwin and Ford (1988) indicated that training-input factors include training design, trainee characteristics and work environment characteristics. According to them, the latter include climatic factors such as supervisory or peer support, as well as constraints and opportunities to perform learned behaviours on the job. Scholars agree that there is a transfer problem because the large amount of resources expended on training hardly pays off (Holton, Bates and Ruona, 2000; Holton, Bates, Bookter and Yamkovenko, 2007).

One cannot but echo some of the questions asked by Subedi (2004): What causes training success or failure? What are the factors that facilitate or inhibit the transfer process? Why do most training programmes and courses fail to facilitate transfer?

In an attempt to answer some of these questions, the researchers fused Baldwin's Transfer of Training Model in relation to the workplace environment with the second level of Kirkpatrick's model.

Baldwin and Ford (1988) were two of the earliest scholars to highlight transfer of training. In their bid to describe the transfer process, they identified training input factors, training outcomes and conditions of transfer. The training input factors are training design, trainee characteristics and work environment characteristics. Work environment characteristics are the focus of this study.

According to Baldwin and Ford, work environment characteristics that are important for transfer of training consist of supportive organizational climates, pre-course discussions with supervisors or managers, opportunities to use knowledge and skills, and post-training goal-setting and feedback. Hence, to the researchers, transfer of training is a process of facilitating efforts to make use of the learned behaviours leading to better results in the post-training context. Other scholars' attempts to define transfer of training are not far from this (Baldwin and Ford, 1988; Subedi, 2004).

Supervisors act as gatekeepers for employees to apply learned skills on the job through their support (Holton et al., 2000). The extent to which the supervisor behaves in ways congruent with the training objectives will have a major impact on the transfer of trained skills by subordinates. 


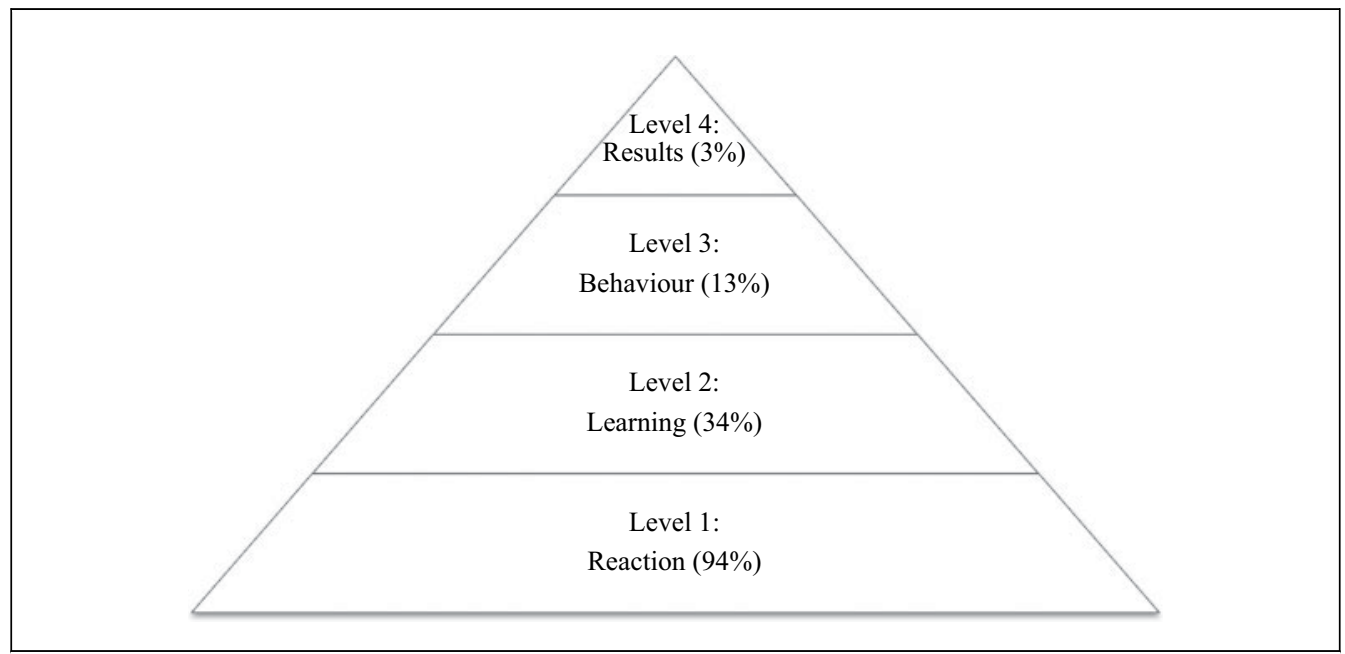

Figure 1: The percentage of research at each level of the Kirkpatrick Training Evaluation Model.

\section{The Kirkpatrick Training Evaluation Model}

The Kirkpatrick Training Evaluation Model (see Figure 1) was developed by Donald Kirkpatrick in 1959 (Kirkpatrick, 1994, 1996), and has been used for decades to evaluate commercial training programmes. He was credited with being the first to apply intentional evaluation to workplace training efforts (Bozarth, 2008).

As seen in Figure 1, the model has four levels, which indicate reaction, learning, behaviour and results (Kirkpatrick, 1994, 1996). Although praised for his initial attempts, the model has been plagued with criticism. This includes the fact that his taxonomy evaluates everything after it has happened, focusing too much on end results, while gathering little data that will help inform efforts to improve training programmes (Bozarth, 2008).

Many authors have been accused of stopping at Level 1 of Kirkpatrick's model (reaction), which leads to the use of 'smile sheets'. These sheets measure the perception of the participants of the training that they received (examples are their like or dislike of it and the relevance of the training to their work). Though deemed as important, its sole use prevents the maximization of the model (Nickols, 2005). In support of this, Rossett (2009) asserted that the percentage of research conducted at each of Kirkpatrick's four levels shows that $94 \%$ of training evaluation research happens at Level 1 (reaction), which leads to 'smile sheets' not really showing the depth of the impact of the training received by 
trainees; 34\% happens at Level 2, where 'learning' takes place as a result of training; 13\% happens at Level 3, which evaluates change in 'behaviour' as a result of the training received; while only 3\% evaluates the 'results' (Level 4) (see Figure 1).

Thus, researchers did not do the model justice. On the other hand, diverse models (Subedi, 2004) have been developed after Kirkpatrick's in order to compensate for some of the shortcomings identified by scholars.

\section{The fusion of Kirkpatrick's Training Evaluation Model and Baldwin's Transfer of Training Model}

Even though Kirkpatrick's Training Evaluation Model has been used extensively, tends to strive for declarative outcome measures, yet provides little information about the reasons for the outcomes (Bozarth, 2008). It is mostly learner-focused and fails to consider contextual or environmental variables of the work environment. Baldwin and Ford (1988), in their literature review on the transfer of learning, identified two research gaps: the need to test various operationalizations of the training design and work-environment factors, and the need to develop a framework to conduct research on the effects of trainee characteristics on transfer. This study focuses on work-environment factors.

With regard to the work-environment, Baldwin and Ford identified the support trainees get and the opportunity to put what they have learnt to use. Therefore, the authors of this paper developed a model to fuse the work-environment characteristics of Baldwin and Ford's description of the training input factors into the third level of Kirkpatrick's model (transfer). This model is depicted in Figure 2.

In the model depicted in Figure 2, the researcher highlights the relationship between programmes, programme outcomes (which should be determined by the national needs that institutions are expected to support, the institutional goals and graduates' aspirations) and programme evaluation. The argument for the model is that, in order to evaluate the success of any educational programme, the programme outcomes, institutional goals and graduates' aspirations need to be aligned with the national goals of the particular country in which the programme takes place (Aluko, 2009).

For training to be transferred, the workplace culture and climate, which may be institutional or systemic, also play a key role. Both would inadvertently go a long way to determine how successful an educational programme has been, and what kind of graduates would be in practice. 


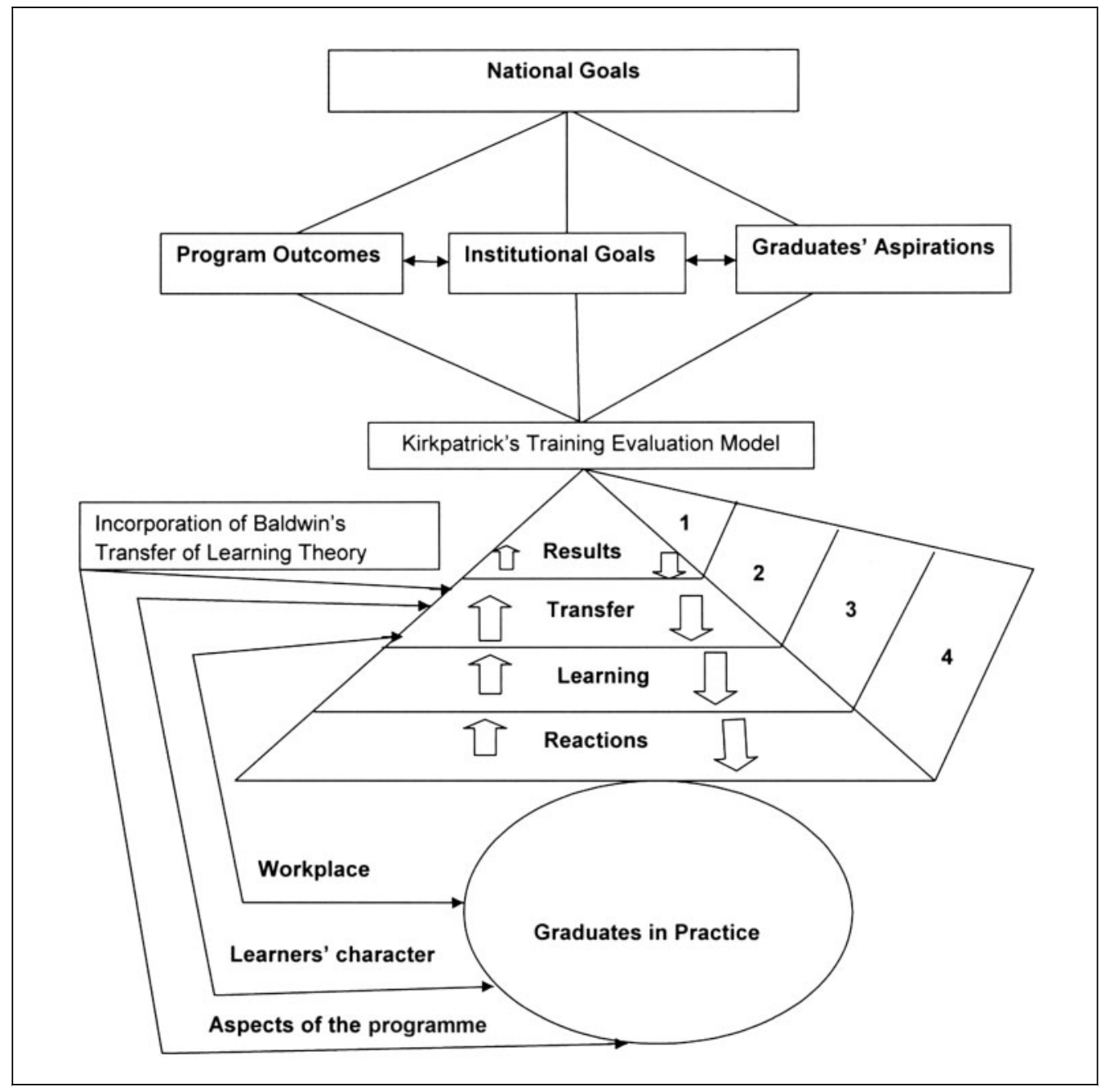

Figure 2: Fusion of two training evaluation models and their relationship to the evaluation of an educational programme.

In order to determine the role of workplace factors in learning transfer and the usefulness of the new model suggested by the researchers to highlight these factors, the following research design was implemented.

\section{Research design}

Methodology

The researchers used a mixed-methods research design using a combination of two surveys (one for graduates and one for the school principal), and individual 
and focus group interviews. The researchers opted for this research design to capitalize on the strengths of both qualitative and quantitative methods, which enabled them to compensate for the weaknesses of each approach (Punch, 2005). They also chose both methods to gain an in-depth understanding of the phenomenon and to avoid skewed findings (Newcomer and Allen, 2008). However, in this article, we focus on the qualitative aspect of both instruments used for the study as they are directly related to the theme of this article.

\section{Instruments}

Two surveys, similar to those previously used for the pilot study in which 200 graduates and 18 principals participated (Aluko 2009), were used for the study. Graduate respondents used Survey 1 and principal respondents used Survey 2. Question items for the surveys were mostly open-ended, which places the responsibility for ownership of data firmly in the respondents' hands (Cohen, Manion, and Morrison, 2000). Some closed questions were included where necessary to elicit fixed responses from the respondents, for example, the questions relating to contextual information.

\section{Validity and reliability of the instruments}

To ensure content validity of the instruments, the questions were based on the stated outcomes of the academic programme with a focus on Kirkpatrick's Training Evaluation Model and Baldwin's Transfer of Training Model. With reference to both models, the researchers developed a schematic diagram that shows the dependent relationships between the outcomes of a programme, which should be determined by national needs that institutions are expected to support, the aspirations of incoming students, and programme evaluation. This relationship is depicted in Figure 3.

The researchers also developed key indicators for national outcomes, as well as those of the University to evaluate the impact of the study programme on the professional practice of graduates. These indicators included graduates' personal development, classroom practice, ability to adapt and implement new policies, ability to play leadership roles, and the effect of graduates' knowledge on their colleagues at work.

\section{Target group and sampling}

For this study, the researchers used multi-stage and purposive sampling techniques to identify prospective participants (Punch, 2005). The target was 


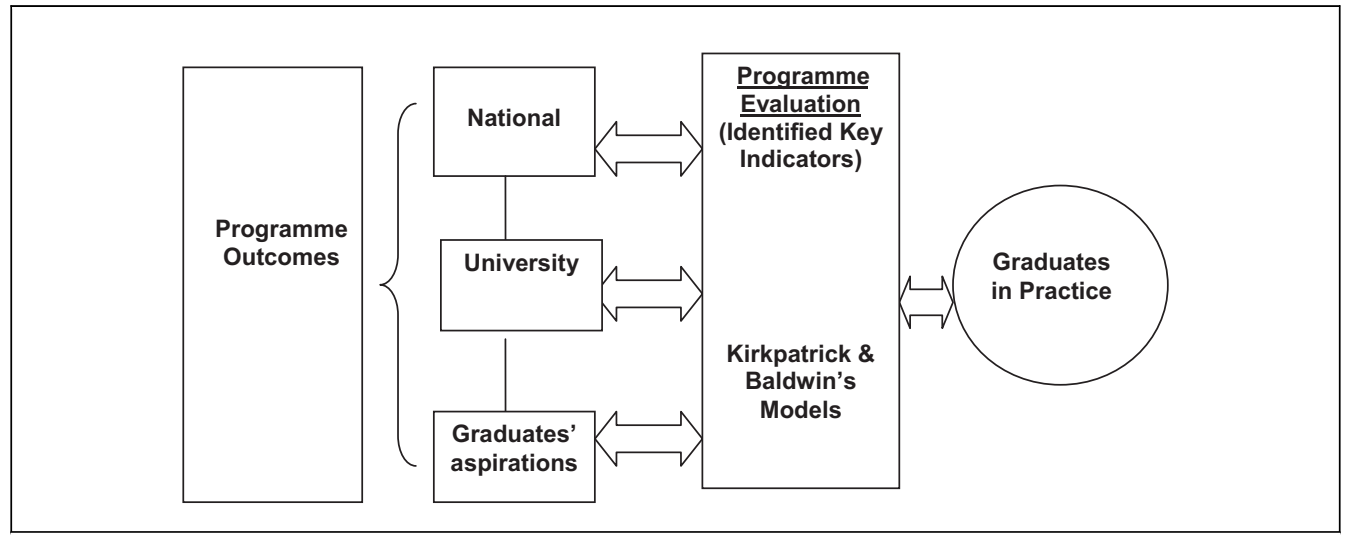

Figure 3: Understanding the relationship between programme, programme outcomes, and programme evaluation.

to reach all the graduates from the five provinces from which the most students enrolled for the Advanced Certificate in Education: Education Management programme. These are the Eastern Cape, Gauteng, KwaZulu-Natal, Limpopo and Mpumalanga. Of the 3438 (2004-2006 cohorts) who graduated from the programme, $2400(69.8 \%)$ were from these provinces. The researchers' reason for the choice of the cohorts was to ensure that the participants would have had ample time to put what they had learnt from the programme into practice. Thus, Survey 1 was sent to the 2400 graduates (through surface mail and on-site collection during contact sessions from those who were already enrolled for the Bed Hons programme). The target group for Survey 2 was the principals identified by willing participating graduates.

\section{Ethical issues}

With regard to ethical issues, the University of Pretoria's Unit for Distance Education operates according to the ethical clearance certificate for conducting research into distance education programmes issued by the Ethics Committee of the University's Faculty of Education. A short message (SMS) had also been sent to would-be graduate participants earlier to inform them about the study and its purpose. In the message, the researchers told the graduates that participation was voluntary. The researchers also attached a letter of informed consent as the front page of the surveys, which willing participants were expected to sign and return with their completed survey. The implications of the non-confidential nature of Survey 2 were explained to those graduates who might be willing to let the researchers contact their principals or line managers. 


\section{Procedure for data collection}

\section{Survey 1 and Survey 2}

The researchers sent Survey 1 first. This contained questions about the graduates' biographies, their motivation for study, the value of the programme and their ability to transfer what they had learnt to their work environment. The survey was sent to all the identified graduate respondents through surface mail due to the fact that they were mostly scattered in the rural areas of the identified provinces with little or no access to the Internet. Each package included a postage-paid return envelope. The particulars of the graduates were received from the administrative section of the Unit for Distance Education. This was made possible due to the ethical clearance certificate already issued to the Unit for Distance Education by the Faculty of Education. A follow-up SMS was sent to participants to remind and encourage them to complete the surveys and to return them on time. The researchers received $300(12.5 \%)$ responses, while 164 $(56.6 \%)$ of these indicated that they wanted the researchers to contact their principals.

Survey 2 was sent to the 164 identified principals. In the survey, the researchers requested information on the principals' biographies and what they thought the impact of the programme was on the professional development of the identified graduates. Of the principals, $128(78 \%)$ returned the questionnaires. They were asked to indicate the name of the graduate on behalf of whom they were completing the questionnaire. Although this compromised the level of confidentiality, it was unavoidable due to the purpose of the study.

\section{One-to-one interviews}

The researchers initially planned to conduct focus group interviews only. However, this was impractical since two of the principals were hundreds of kilometres apart from the rest. One-to-one interviews were thus conducted with these two principals.

\section{Focus group interviews}

The focus group interviews took place in all the provinces selected for the study. The researchers asked questions to validate some of the trends that emerged from the surveys. Five focus group interviews were conducted, involving 30 teachers, while another five were conducted involving 17 school principals and one vice principal. In order to mobilize the participants, the researchers made several phone calls and also sent reminders via SMS. 
The number of participants in each group ranged from between four and seven. The researchers obtained permission from the participants to record the interviews. The researchers also gave the participants informed consent forms to sign before each interview commenced. Participants could withdraw their participation if they felt they did not want to continue with the interview.

\section{Data analysis}

The interview data was analysed with the Computer-Assisted Qualitative Data Analysis software Atlas.ti 5.0. Relevant quotations and codes were identified based on the concepts and themes frequently mentioned by interviewees (Hardy and Bryman, 2004). In addition, codes were developed for the open-ended questions after the respondents' questionnaires had been returned, while the University of Pretoria's Department of Statistics analysed the few quantitative aspects of the questionnaires to arrive at the cumulative frequencies and cumulative percentages. The codes for both the surveys were in line with the identified key indicators. The planning, implementation, analysis, and reporting of the project findings took place from February 2010 to October, 2012.

\section{Main findings from the investigations, discussion and limitations}

Based on the suggested model developed by the researchers, the focus of the study was on the extent to which the graduate participants were able to transfer what they had learnt from the programme to their workplace.

The researchers derived the suggested model from Level 2 of Kirkpatrick's model (transfer), and one of the aspects to consider in graduates' ability or inability to transfer learning from Baldwin and Ford's Learning Transfer Theory (workplace). Halpin and Croft $(1963,1)$ summed work characteristics up as 'organizational climatic factors', and construed them as the 'personality' of a school in which, figuratively, 'personality' is to the individual what 'climate' is to the organization. Thus, the researchers discuss the main findings of the investigations according to peer support and supervisory support, which are directly linked to the constraints and opportunities to perform learned behaviours on the job (Baldwin and Ford, 1988).

\section{Peer support}

In terms of peer support, $280(93 \%)$ of the 300 graduate participants indicated that they received good peer support 'to a large extent' from their colleagues, while $20(7 \%)$ indicated that they received peer support 'to some extent'. The 
main reason given by the respondents who received good peer support to a large extent was the improvement in their professional practice. This was evident in the graduates' ability to manage time and conflict better; improved relationships between graduates and parents, and graduates and their colleagues; and the implementation of education policies (such as the abolishment of corporal punishment in schools). Thus, they indicated that they served as role models to motivate their peers, who later enrolled for the programme. Most of what they said was corroborated by the principal participants. One of them indicated that this had 'helped to enhance the quality of the school', while most of them agreed with the principal who asserted that 'there was a vast difference between those who graduated from the programme and those who did not'. Research indicates that a lack of peer support is one of the barriers that dissuades training transfer behaviours (Hatala and Fleming, 2007).

\section{Supervisory support}

During the focus group interviews, some of the graduate participants indicated that most of the challenges they experienced were with the principals. Some of the graduates hinted at 'lack of delegation on the part of their principals', 'some principals felt it was degrading to delegate to some of the graduate participants', 'the belief that teachers who had attended the programme were not on the level where they could participate in school management', while 'some principals never encouraged their teachers to enrol', which made some principals 'becoming hateful'. Other reasons given were the 'rigidity of school principals to adapt to new ways of thinking', 'ineffective leadership styles' and 'feeling of intimidation of the new educational level' of some participants. Some graduate participants were highly emotional about their frustrations.

On the other hand, some principal participants cited 'pride' on the part of some graduates, 'inability to take up new responsibilities' and the 'laziness' of some graduates as possible reasons for learning not being transferred in the workplace.

Kenney et al. (1967) described the phenomenon of supportiveness as a measure of the principal's leadership behaviour, which is reflected in the extent of teacher involvement and satisfaction in the school. In other words, the organizational climate of schools has a strong influence on the transfer of learning. One of the legacies that has been left by the political history of South Africa is poor school management that has led the democratically elected government to opt for school-based management (Steyn, 2002). Thus, new educational policies in the country require educational managers who are able to 
work in democratic and participative ways to build relationships and ensure the effective delivery of education (South Africa, 1996). Management is not just a matter of systems. It is mainly a matter of people and relationships, focused around clear organizational aims and tasks that should be performed to realize those aims (Law and Glover, 2000).

However, the researchers are of the opinion that all the blame should not be solely laid at the principals' feet, because trainee characteristics such as ability or skill, motivation and personality factors also play important roles in the transfer of training (Baldwin and Ford, 1988). Unfortunately, the aspect of trainee characteristics is beyond the scope of this article.

\section{Constraints and the opportunities to perform learned behaviours on the job}

There is a symbiotic relationship between supervisory support and the constraints and opportunities for graduates to perform learned behaviours on the job. Constraints may include a lack of resources (which is work-system related) or people-related factors (Handy, 2008).

During the focus group interviews for graduate participants, affected graduates cited the people-related factor (especially with regard to their principals) as a major constraint. Critical reflection has been linked to one of the characteristics of adult learners (self-directed learning) (Smith, 2002). Knowledge that is not applied is unusable. Thus, the critical social theorists would argue that the implicit goal of the theory is the emancipatory function of knowledge (Leonardo, 2004). Teachers defeat this goal when they cannot transfer their learning to the workplace due to bureaucracy or internal wrangling. According to Ekey (2012), transference is most likely to occur in the following situations: association, similarity, degree of original learning, and in the presence of the critical attribute element.

To buttress all these, findings from a study conducted by Van der Mescht and Tyala (2008) suggest that some principals may find it hard to 'let go', citing reservations to trust all of their colleagues, and a fear of being let down as possible reasons for their lack of a team management approach. The researchers hope that various training and upgrading programmes that have been introduced by the Department of Education will go a long way to alleviate these challenges on the part of some principals. This is in view of the fact that a global mindset shift is being encouraged in the field of management. 
On the other hand, opportunities from the supervisors to perform learned behaviours on the job may come in the form of encouragement to use newly learned behaviour, assistance in identifying situations where the behaviours can be used, guidance and feedback on properly applying new behaviours, sufficient practice and holding trainees accountable to apply newly acquired behaviours (Handy, 2008).

Graduate participants who enjoyed good support, as indicated by Handy, explained that they were 'encouraged by their principals to take up delegated responsibilities'. Some also started fresh projects such as soup kitchens, vegetable gardens and rendering support to HIV/AIDS children and childheaded homes. These projects were encouraged by one of their assignments during the programme.

From the findings above, the researchers stress the importance of not just stopping at 'smile sheets' to evaluate the impact of distance education programmes on the professional development of graduates. This is done by identifying some of the factors that could limit or encourage graduates' abilities to transfer learning behaviour. Nonetheless, there are some limitations.

Firstly, a possible challenge could be the assumption that some of the graduates (164) who suggested the names of the principal participants were in the 'good books' of their principals (although many of the principals vehemently denied this). Secondly, the positive impact of the programmes on some of the graduates' professional development might have been due to other training interventions (such as those organized by the Department of Education). These are conditions that were beyond the control of the researchers.

\section{Conclusion}

This research was initiated to examine the role played by workplace factors in learning transfer and to establish to what extent the fusing of the different levels of the two models on the evaluation of training suggested by the researchers has helped to highlight these factors.

Based on the findings of the study, the researchers agree with other scholars that the workplace environment, along with other personal factors, play a major role in trainees' abilities to transfer their acquired experience to the work environment. It also appears that there is a need for a shift in the mindset of school principals with regard to the value that teachers who have upgraded their certificates could add to the workplace environment. The researchers conclude 
that the support trainees get will determine the extent to which they are able to put what they have learnt to use. On the other hand, some principal participants indicated that teachers also need to develop positive characteristics (such as 'respect', 'humility' and 'ability to work with others') that would enable principals to work with them. It is only then that the full potential of distance education programmes for the upgrading of teachers' qualifications can be realized.

In addition to this, by fusing together the second level of Kirkpatrick's Training Evaluation Model and Baldwin's Transfer of Training Model (the workplace environment), the researchers have been able to consider some of the factors (peer and supervisory support, constraints and opportunities) that may hinder or promote learning transfer. It is hoped that this will make up for some of the gaps already identified by focusing only on Kirkpatrick's Training Evaluation Model. The researchers also propose that more research should be carried out based on the suggested model.

In relation to this, the researchers are of the opinion that there is a need to go beyond the use of 'smile sheets' alone to determine the impact of training received by participants. However, this means that mixed-methods research design that focuses more on qualitative methods should be adopted. This would help researchers to carry out in-depth studies into the factors that limit or promote learning transfer.

Although much research has been done on transfer of learning in other public sectors since the research gaps identified by Baldwin and Ford (1988), there is still more work to be done on this phenomenon in the education sector, which is also related to the evaluation of such programmes, especially those meant for teachers. This is more so because distance education programmes are being widely used for initial teacher training and upgrading. Since much money is being spent on education, there is a need to encourage ROI. The researchers also call for a separate neutral study into the extent of support given to educators by their principals after their study and what opportunity trainees have to put the experience they have gained to use. Research has shown that supervisors may have emotional links (either positive or negative) with participants, thus creating potential obstacles and bias (Galloway, 2005).

\section{Funding}

This work was supported by Research Development Project (RDP), University of Pretoria, Pretoria, South Africa [grant number A0S177]. 


\section{Notes on contributors}

F. R. Aluko is the Researcher \& Instructional Design Supporter at the Unit for Distance Education, Faculty of Education, University of Pretoria, Pretoria, South Africa.

O. K. Shonubi was a doctorate student in the Department of Education Management, Law \& Policy Studies, Faculty of Education, at the same university department of EMLP.

\section{References}

Aluko, F. R. 2009. The impact of an Advanced Certificate in Education programme on the professional practice of graduates. The International Review of Research in Open and Distance Learning, 10 (4): www.irrodl.org.

Baldwin, T. T. and J. K. Ford. 1988. Transfer of training: a review and directions for future research. Personnel Psychology, 41 (65): 63-105.

Boyle, M. and R. Crosby. 1997. Academic programme evaluation: lessons from business and industry. Journal of Industrial Teacher Education, 34 (3): http://scholar.lib.vt.edu/ejournals/JITE/v34n3/AtIssue.html.

Bozarth, J. 2008. From analysis to evaluation: tools, tips and techniques for trainers. Hoboken, NJ: Wiley Publishers.

Cohen, L., L. Manion and K. Morrison. 2000. Research methods in education, 5th ed. London: Routledge.

Ekey, C. 2012. Literacy coaches training. Available at: http://carrieekey.com/ handouts/Rotterdam2012/Eu_Coaches_Conf2_Rott_Day_1_A4.pdf [Accessed 3 December 2012].

Fahy, P. J., B. Spencer and T. Halinski. 2007. The self-reported impact of graduate programme completion on the careers and plans of graduates. Quarterly Review of Distance Education, 9 (1): 51-71.

Galloway, D. L. 2005. Evaluating distance delivery and e-learning: is Kirkpatrick's model relevant? Performance Improvement, 44 (4): www. ispi.org.

Guskey, T. R. 2000. Evaluating professional development. Thousand Oaks, CA: Corwin Press.

Halpin, A. W. and D. B. Croft. 1963. The organizational climate of schools. Chicago, IL: Midwest Administration Center, University of Chicago.

Handy, L. A. W. 2008. The importance of the work environment variables on the transfer of training. Raleigh, NC: North Carolina University, ProQuest.

Hardy, M. and A. Bryman. 2004. Handbook of data analysis. Thousand Oaks, CA: Sage Publications. 
Hatala, J. and P. R. Fleming. 2007. Making the transfer climate visible: utilizing social network analysis to facilitate the transfer of training. Human Resource Development Review, 6 (1): 1-31.

Holton III, E. F., R. A. Bates and W. Ruona. 2000. Development of a generalized learning transfer system inventory. Human Resource Development Quarterly, 11 (4): 333-360.

Holton III, E. F., R. A. Bates, A. I. Bookter and V. B. Yamkovenko. 2007. Convergent, divergent validity of the learning transfer system inventory. Human Resource Development Quarterly, 18(3): 385-419.

Kenney, J. B., W. F, White and H. W. Gentry. 1967. Personality characteristics of teachers and their perception of organizational climate. Journal of Psychology, 66 (2): 167-174.

Kirkpatrick, D. L. 1994. Evaluating training programmes: the four levels. San Francisco, CA: Berrett-Koehler Publishers.

Kirkpatrick, D. L. 1996. Evaluating training programmes: the four levels. San Francisco, CA: Berrett-Koehler Publishers.

Kovach, M. and M. H. Montgomery. 2010. What kind of learning? For what purpose? Reflections on a critical adult education approach to online social work and education courses serving indigenous distance learners. Critical Social Work, 1 (1). http://www.uwindsor.ca/criticalsocialwork/what-kind-oflearning-for-what-purpose-reflections-on-a-critical-adult-education-approachto-online-.

Law, S. and D. Glover. 2000. Educational leadership and learning: practice, policy and research. Philadelphia, PA: Open University Press.

Leonardo, Z. 2004. Critical social theory and transformative knowledge: the functions of criticism in quality education. Educational Researcher, 33 (6): $11-18$.

McKee, T. 2010. Thirty years of distance education: personal reflections. The International Review of Research in Open and Distance Learning, 11 (2). www.irrodl.org.

Musset, P. 2010. Initial teacher education and continuing training policies in a comparative perspective: current practices in OECD countries and a literature review on potential effects. OECD Education Working Papers, No. 48, OECD Publishing. http://dx.doi.org/10.1787/5kmbphh7s47h-en.

Newcomer, K. E. and H. Allen. 2008. Adding value in the public interest. Available at: www.naspaa.org/accreditation/standard2009/docs/AddingValu einthePublicInterest.pdf [Accessed 5 October 2011].

Newstrom, J. W. 1984. A role-taker time differentiation integration of transfer strategies. A Paper presented at the meeting of the American Psychological Association, Toronto: Ontario, 24-28 August. 
Nickols, F. 2005. Why a stakeholder approach to evaluating training. Advances in Developing Human Resources, 7 (1): 121-134.

Organisation for Economic Cooperation and Development. 2005. Teachers matter: attracting, developing and retaining effective teachers. Paris: OECD Publishing.

Punch, K. 2005. Introduction to social research: quantitative and qualitative approaches, 2nd ed. London: Sage.

Rossett, A. 2009. Beyond Kirkpatrick: taking a fresh look at analysis and evaluation. The eLearning Guild's Instructional Design Symposium, Chicago, Illinois.

Rumble, G. 2007. Social justice, economics and distance education. Open Learning: The Journal of Open, Distance \& e-Learning, 22 (2): 167-176.

Smith, M. K. 2002. Malcolm Knowles, informal adult education, self-direction and anadragogy. The Encyclopedia of Informal Education. www.infed.org/ thinkers/et-knowl.htm.

South Africa. 1996. Report on the task team on education management development. Department of Education. Pretoria: Government Printer.

South Africa. 2000. Norms and standards for educators. Department of Education. Available at: http://www.polity.org.za/html/govdocs/notices/2000/not0082.html [Accessed 5 October 2011].

South Africa. 2001. National plan for higher education. Pretoria: Department of Education.

South Africa. 2012. South Africa spends more on education. Available at: http:// www.southafrica.info/about/education/budget2012-education.htm [Accessed 4 June 2010].

Steyn, G. M. 2002. The changing principalship in South African Schools. Educare, 31 (1-2): 251-274.

Subedi, B. S. 2004. Emerging trends of research on transfer of learning. International Education Journal, 5 (4): 591-599.

Swanepoel, C. 2008. The perceptions of teachers and school principals of each other's disposition towards teacher involvement in school reform. South African Journal of Education, 1 (28): 39-51.

Tarouco, L. and L. Hack. 2000. New tools for assessment in distance education. Available at: http://www.pgie.ufrgs.br/webfolioead/artigo1.html [Accessed 5 October 2011].

Training Magazine. 2011. Training industry report. Available at: http://www. trainingmag.com/article/2011-training-industry-report [Accessed 5 October 2012].

UNESCO (United Nations Educational, Scientific and Cultural Organisation). 2001. Teacher education through distance learning: technology, curriculum, 
evaluation, cost. Paris: Education Sector, Higher Education Division, Teacher Education Sector.

UNESCO (United Nations Educational, Scientific and Cultural Organisation). 2009. Trends in global higher education: tracking an academic revolution. Paris: UNESCO.

University of Pretoria. 2011. Advanced certificate in education: education management-distance education programme. Pretoria: University of Pretoria.

Van der Mescht, H. and Z. Tyala. 2008. School principals' perceptions of team management: a multiple case-study of secondary schools. South African Journal of Education, 28 (2): 221-239. 